\title{
Occupational exposure to silica dust and risk of lung cancer: an updated meta- analysis of epidemiological studies
}

Satiavani Poinen-Rughooputh ${ }^{1,2}$, Mahesh Shumsher Rughooputh ${ }^{3}$, Yanjun Guo ${ }^{1,2}$, Yi Rong ${ }^{1,2}$ and Weihong Chen ${ }^{1,2^{*}}$

\begin{abstract}
Background: Crystalline silica is considered as one of the most common and serious occupational hazards to workers' health. Although its association with lung cancer has been studied for many decades, the conclusion remains somewhat controversial. Our objectives are to review and summarize the epidemiological evidence on the relationship between occupational silica exposure and risk of lung cancer and to provide an update on this major occupational health concern.
\end{abstract}

Methods: Eligible studies up to 29 April 2016 were identified. Pooled effect estimates were calculated according to the reported outcome and the study design. Cohort, case control and proportional mortality studies were examined separately. Studies reporting results according to silicotic status were grouped together and analyzed. Due to the significant amount of heterogeneity expected, random effects models were implemented. Subgroup and metaregression analyses (both univariate and multivariate) were performed in an attempt to explain heterogeneity. Studies which had adequate exposure characterization were selected to find out whether there was an exposureresponse relationship between silica and lung cancer.

Results: The risk of lung cancer was found to be elevated in both silicotics and non-silicotics. The pooled standardized mortality ratio (SMR) was 2.32 with a $95 \%$ confidence interval (95 \% Cl) of 1.91-2.81 and 1.78 (95\% Cl 1.07-2.96) respectively. The pooled standardized incidence ratio (SIR) was 2.49 (95 \% Cl 1.87-3.33) and 1.18 (95\% Cl 0.86-1.62) respectively. Subgroup analysis showed that workers in the mining industry had the highest risk of lung cancer with a pooled SMR of 1.48 (95 \% Cl 1.18-1.86) and the weakest association was seen in potteries with a pooled SMR of 1.14 ( $95 \% \mathrm{Cl}$ 1.05-1.23). A positive exposure-response relation was found between cumulative silica exposure and risk of lung cancer.

Conclusion: The results of our meta-analysis supported the carcinogenic role of silica on the lungs, which was more pronounced at higher levels of exposure, in the presence of silicosis and in the mining industry. Further research is needed to evaluate whether non-silicotics are truly at risk, whether a predisposing factor would explain this potential risk, and to determine the mechanism of carcinogenicity of silica in humans.

Keywords: Silica, Silicosis, Lung cancer, Meta-analysis, Heterogeneity, Meta-regression, Exposure-response analysis

\footnotetext{
* Correspondence: wchen@mails.tjmu.edu.cn

'Department of Occupational \& Environmental Health, School of Public Health, Tongji Medical College, Huazhong University of Science and Technology, Wuhan, Hubei 430030, China

${ }^{2}$ Key Laboratory of Environment and Health, Ministry of Education \& Ministry

of Environmental Protection, and State Key Laboratory of Environmental

Health (Incubating), School of Public Health, Tongji Medical College,

Huazhong University of Science and Technology, Wuhan, Hubei 430030,

China

Full list of author information is available at the end of the article
} 


\section{Background}

Crystalline silica is one of the commonest minerals on earth and a major ingredient in sand, granite, soil and glass. Traditionally, silica exposure occurs in workplaces such as coal and metal mining, metallurgy, construction industry and manufacturing of building materials, glass and clay. Recent reports indicated that more than 33 million workers in China [1] and India [2], more than 3.2 million workers in Europe [3] and about 1.7 million workers in the United States [4] are exposed to crystalline silica dust. Currently, environmental exposure to ambient silica dust caught more attention, not only during agricultural activities, but also during natural sandstorms and volcanic explosions $[5,6]$. Silica exposure causes many adverse health effects including silicosis, cardiovascular diseases, tuberculosis, malignancies, autoimmune diseases and renal disorders and increased mortality, making it a high-priority public health concern [7].

The possible carcinogenicity of silica became a subject of intense debate in the scientific community in the 1980s, especially after the publication of epidemiological studies by Westerholm in 1980 [8] and Finkelstein et al. in 1982 [9], a literature review by Goldsmith et al. in 1982 [10] and presentation of new information at a 1984 symposium in North Carolina [11]. This triggered the publication of further studies on cancer mortality and morbidity in silica-exposed occupational groups. In 1997, based on a review of these studies, the International Agency for Research on Cancer (IARC) classified crystalline silica in the form of quartz or cristobalite as carcinogenic to humans (Group 1) [12]. However, the IARC working group also stated that the carcinogenicity was not found in all industrial circumstances, and their conclusion remained somewhat controversial.

The latest IARC report in 2012 reported seven metaanalyses conducted on this topic [13]. We noted that the issue of between-study heterogeneity was either not addressed at all or not dealt with in sufficient detail in these meta-analyses. Also, since the publication of the last meta-analysis on the relation between occupational silica exposure and lung cancer in 2009, more than 10 potentially relevant epidemiological studies have been conducted.

In our paper, we have combined epidemiological data from relevant studies published till date to evaluate the risk of lung cancer due to silica dust exposure and we have attempted to explain heterogeneity through subgroup and meta-regression analyses. We have also performed an exposure-response analysis by identifying studies which had well-characterized exposure data.

\section{Methods}

The meta-analysis was conceived and performed in accordance with the Preferred Reporting Items for
Systematic Reviews and Meta-Analyses (PRISMA) guidelines [14].

\section{Search strategy}

We searched MEDLINE and EMBASE databases from January 1982 through 29 April 2016 using the search terms "lung cancer", "silica", "silicosis", "risk", "incidence" and "mortality" with variation in term construct to identify epidemiological studies published in the literature which evaluated the relationship between silica exposure and lung cancer in workers, irrespective of their silicotic status (Additional file 1). Reference lists of the identified articles were also screened for potentially eligible studies.

The following inclusion criteria were used for the analysis:

- The article had to have been published in English;

- The study had to have had a cohort or case-control or proportional mortality study design;

- Lung cancer should have been reported as a major outcome;

- The article had to have reported original results along with confidence intervals in the form of standardized mortality ratio (SMR) or standardized incidence ratio (SIR) or odds ratio (OR) or proportional mortality ratio (PMR) or mortality odds ratio (MOR) or relative risk (RR) with their corresponding $95 \%$ confidence interval.

Reviews, autopsy studies, comments, editorials, studies with insufficient quantitative data required for the analysis (no risk estimate, no confidence intervals) and those overlapping with studies which were already considered, were excluded.

When a particular study was reported in several papers, the most recently-published reference was used unless the required data was reported in a previous paper and not in the latest-published one.

\section{Data extraction}

For each study, the following data was extracted: geographical location, year of publication, industrial setting, study design, total number of subjects, exposure assessment (including level and duration of exposure to silica dust), outcome examined, study period (including the start date, end date and duration of follow-up), personyears of follow-up, covariates adjusted for, potential occupational carcinogens including radon, arsenic, asbestos, diesel, polycyclic aromatic hydrocarbons (PAH), talc, cadmium and amphiboles, number of lung cancer cases, total number of deaths and number of deaths due to lung cancer, measure of association and effect estimates with corresponding $95 \%$ confidence interval (CI). 
Two authors worked independently for study selection and data extraction. Any disagreement was resolved after a team discussion. The list of included studies was made in consensus.

\section{Assessing study quality}

We used the Newcastle-Ottawa Assessment Scale (NOS) for assessing the methodological quality of observational studies [15]. The scale consists of three main categories including selection of study population, comparability of subjects and ascertainment of exposure for case-control studies or ascertainment of outcome for cohort and proportional mortality studies. Scores of $0-3,4-6$ and 7-9 were assigned to low, moderate and high quality studies respectively.

\section{Statistical analysis}

Studies were pooled together according to the outcome examined which could be incidence or mortality, the study design which could be cohort or case-control or proportional mortality study design and the measure of association. When a study reported results stratified by race, gender, industrial setting and silicotic status, they were treated as two separate reports for analysis. Studies which gave risk estimates according to silicotic status were grouped and analyzed separately. Statistical analysis was performed on the natural logarithm $(\mathrm{ln})$ of the risk estimate so as to approximate its sampling distribution to a normal one. The difference between the upper and lower limits of the confidence intervals was transformed to the $\log$ scale and the standard error was calculated by dividing the transformed interval by 3.92 [16]. Random effects model was used to calculate the pooled effect estimates since a high level of heterogeneity was expected. Heterogeneity between studies was quantified by two methods namely the chi-squared test ( $\mathrm{Q}$ test) for heterogeneity, reported by its $p$ value, and the variability due to heterogeneity ( $\mathrm{I}^{2}$ statistic), reported as a percentage in this paper [17]. We performed subgroup and meta-regression analyses to try to explain any observed between-study heterogeneity. In subgroup analysis, the studies were categorized into subgroups based on the predefined covariates. In meta-regression, we investigate the relationship between the covariates and the observed outcome [18]. The proportion of variance explained $\left(R^{2}\right)$ was used to quantify the amount of heterogeneity accounted for by each covariate. It was calculated as the percentage of ratio of variance explained to the total amount of variance. Both univariate and multivariate meta-regression models were used to try to lower the variability due to heterogeneity $\left(\mathrm{I}^{2}\right)$ to the minimum level and to bring the $p$ value of $\mathrm{Q}$ close to 1 . Heterogeneity should be completely absent $\left(\mathrm{I}^{2}\right.$ is 0 and $p$ value of $\mathrm{Q}$ is 1) for an ideal comparison [19]. Differences in exposure assessment, study design and quality, data collection processes, outcome assessment, selection of subjects and definition of confounding factors often account for significant between-study heterogeneity [16]. Based on this statement, the covariates considered were year of publication, presence of at least one confounding factor, adjustment for smoking, industrial setting, geographical location, NOS score, cumulative silica dust exposure level, duration of exposure, concentration of silica dust, person-years of follow-up, number of subjects and total number of deaths. For sensitivity analyses, we assessed the influence of individual studies on the pooled estimate by omitting each study in turn (leave-one-out analysis). Publication bias was assessed graphically by means of funnel plots and quantitatively by Egger's linear regression method [20]. For the exposure-response analyses, we used the average cumulative silica dust exposure as covariate and the risk estimate of the corresponding study as the effect. No imputation was made in relating the effect estimate to the exposure level. Statistical analysis was done using $\mathrm{R}$ software version 3.1.2 (2014-10-31) [21] with the 'metafor' package version 1.9-5 [22].

The levels of significance for all statistical tests were assumed to be equal to or less than 0.05 , except in the case of heterogeneity testing whereby the level of significance was assumed to be equal to or less than 0.10 [17].

\section{Results}

\section{Characteristics of studies and bias assessment}

The PRISMA flowchart for the selection of studies is shown in Fig. 1. The initial search criteria yielded 227 citations from the databases. 58 additional records were further identified from references of related articles. After removing duplicates, we were left with 273 records. Preliminary screening of abstracts eliminated 158 studies. Of the remaining 115 articles, 30 were excluded for the following reasons: 6 articles were found to be either reviews, editorials, comments or autopsy studies, 11 papers had no risk estimate data, 2 articles did not give the confidence intervals of the effect estimate, 2 articles did not report lung cancer as outcome and 9 articles had overlapping populations with selected studies. After exclusion of these 30 studies, 85 articles were left and included in the final main quantitative synthesis [9, 10, 23-104]. The study of Puntoni et al. [105], which was excluded from the main synthesis due to overlap with the study cohort of Merlo et al. [66], was included in the list of silicotic studies since it contained the risk estimate based on silicotic status whereas the study by Merlo et al. had the risk estimate of the whole cohort and not according to silicotic status.

After categorization of the studies by outcome assessed, study type and measure of association there were 63 cohort studies reporting mortality due to lung 


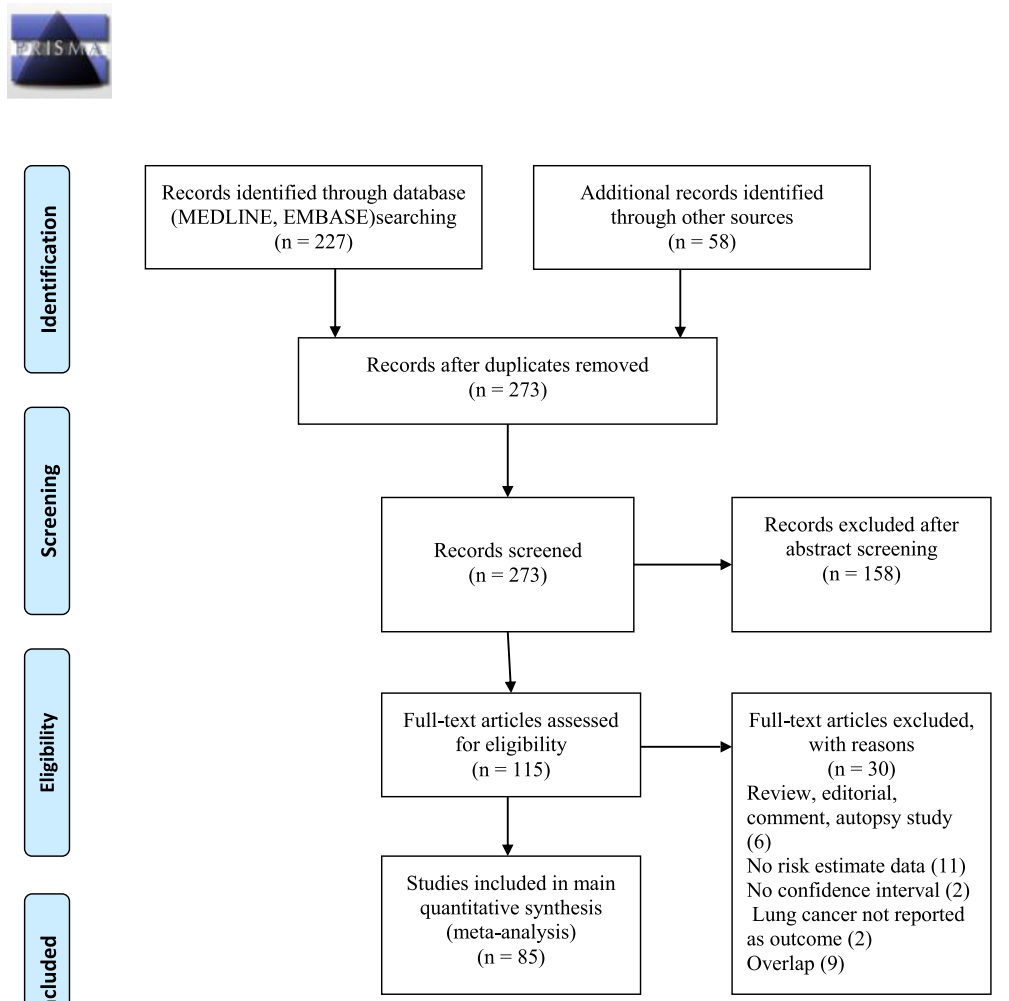

Fig. 1 The PRISMA flowchart for the selection of studies

cancer in the form of SMR as measure of association, 19 cohort studies reporting incidence of lung cancer in the form of SIR, 1 cohort study reporting incidence in the form of RR, 3 case-control studies reporting mortality in the form of MOR, 9 case-control studies reporting incidence in the form of OR, 5 case-control studies reporting mortality in the form of OR and 2 proportional mortality studies or PMR. The characteristics of all included studies are shown in Additional file 2.

Most studies comprised males only and a mere few included both males and a small proportion of females (around $10 \%$ ). Only exceptions were the studies of Zhang et al. [104] and Smailyte et al. [84] with 26 and $31 \%$ women respectively. Nine papers reported 2 or more results stratified by industrial setting, sex, silicotic status and racial background. Forty-one studies were conducted in European countries, 18 in the United States, 21 in Asian countries, 9 in Canada, 3 in Australia and 1 in South Africa. The industries of concern were mining, foundry, pottery and ceramic, refractory brick and diatomaceous earth processing, granite which included sand and quarry, cement production and construction. The total number of studies available for analysis according to silicotic status was 34 . The characteristics of silicotic and non-silicotic studies are described in Table 1.
The results of the study quality assessment are presented in Additional file 3. Ten articles were deemed to be of low quality, 49 articles were found to be of medium quality and 26 articles were shown to be of high quality. The median score for all 85 articles was 5.3 out of a maximum of 9 .

As demonstrated graphically by the funnel plots in Additional files 4, 5 and 6, there was evidence of publication bias for studies reporting mortality in the form of SMR ( $p=0.024$ for Egger's regression test) but no evidence of publication bias for studies reporting incidence in the form of SIR $(p=0.238)$ and OR $(p=0.457)$.

\section{Data analysis}

Using the random effects model, the pooled estimate was 1.55 (95\% CI 1.38-1.75) for SMR studies, 1.68 (95\% CI 1.45-1.96) for SIR studies, 1.10 (95\% CI 0.89-1.36) for PMR studies, 1.69 (95 \% CI 1.26-2.26) for MOR studies, and 1.34 (95\% CI 1.24-1.46) for case-control studies reporting incidence as outcome and 1.82 (95\% CI 1.25-2.66) for case-control studies reporting mortality as outcome. The risk estimate in each category was statistically significant $(p<0.05)$ except in the category of PMR studies $(p=0.38)$. The results of the SMR, SIR and OR studies with incidence as outcome are illustrated in forest 
Table 1 Characteristics of silicotic and non-silicotic studies

\begin{tabular}{|c|c|c|c|c|c|c|c|c|c|}
\hline & Author, Year & Country & Industry & Covariates adjusted for & $\begin{array}{l}\text { Number of } \\
\text { subjects }\end{array}$ & $\begin{array}{l}\text { Outcome } \\
\text { examined }\end{array}$ & $\begin{array}{l}\text { Measure, silicotic } \\
\text { status }\end{array}$ & $\begin{array}{l}\text { Effect Estimate } \\
(95 \% \mathrm{Cl})\end{array}$ & $\begin{array}{l}\text { Obser } \\
\text { cance } \\
\text { or cas }\end{array}$ \\
\hline & Cohort studies & & & & & & & & \\
\hline 2 & Berry, 2003 [28] & Australia & Mixed & Age, sex, calendar period, smoking & 1467 & Mortality & SMR, silicotic & $1.90(1.50-2.30)$ & 94 \\
\hline 3 & Carta, 2001 [31] & Sardinia & Mine \& quarries & Age, sex, calendar period & 724 & Mortality & SMR, silicotic & $1.37(0.98-1.91)$ & 34 \\
\hline 4 & Chan, 2000 [33] & Hong Kong & Mixed & Age, sex, calendar period & 1502 & Mortality & SMR, silicotic & $1.94(1.35-2.70)$ & 33 \\
\hline 5 & Chen, 1992 [34] & China & Mixed & Age, sex & 70179 & Mortality & SMR, silicotic & $1.22(0.90-1.60)$ & \\
\hline \multirow[t]{2}{*}{6} & Chen, 1990 [35] & China & Iron mine & Age, sex & 1226 & Mortality & SMR, silicotic & $5.30(2.90-8.80)$ & 14 \\
\hline & & & & & & Mortality & SMR, non-silicotic & $2.90(1.60-4.70)$ & 15 \\
\hline \multirow[t]{2}{*}{7} & Chen, 2006 [37] & China & Mine & Age, sex & 932 & Mortality & SMR, silicotic & $4.13(3.15-5.29)$ & \\
\hline & & & & & & Mortality & SMR, non-silicotic & $1.96(1.50-2.73)$ & \\
\hline 8 & Chia, 1991 [39] & China & granite & Age, sex, calendar period & 159 & Incidence & SIR, silicotic & $2.01(0.92-3.81)$ & 9 \\
\hline 9 & Chiyotani, 1990 [40] & Japan & Mixed & Age, sex & 1941 & Mortality & SMR, silicotic & $6.03(5.29-6.77)$ & 44 \\
\hline \multirow[t]{2}{*}{11} & Finkelstein, 1995 [43] & Canada & Mixed & Age, sex & 328 & Incidence & SIR, silicotic & $2.55(1.43-8.28)$ & 15 \\
\hline & & & & & & Incidence & SIR, non-silicotic & $0.90(0.51-1.47)$ & 16 \\
\hline 12 & Goldsmith, 1995 [49] & USA & Mixed & Age, sex, calendar period & 590 & Mortality & SMR, silicotic & $1.90(1.35-2.60)$ & 39 \\
\hline 13 & Infante- Rivard, 1989 [54] & Canada & Mixed & Age, sex, calendar period & 1072 & Mortality & SMR, silicotic & $3.47(3.11-3.90)$ & 83 \\
\hline 14 & Marinaccio, 2006 [63] & Italy & Mixed & Age, sex, calendar period & 14929 & Mortality & SMR, silicotic & $1.10(1.03-1.18)$ & 798 \\
\hline \multirow[t]{2}{*}{15} & Mehnert, 1990 [64] & Germany & quarry & age, sex & 2475 & Mortality & SMR, silicotic & $1.83(0.84-3.48)$ & 9 \\
\hline & & & & & & Mortality & SMR, non-silicotic & $0.91(0.54-1.44)$ & 18 \\
\hline 16 & Merlo, 1995 [67] & Italy & Mixed & Age, sex, calendar period & 450 & Mortality & SMR, silicotic & $3.50(2.44-4.87)$ & 35 \\
\hline 17 & $\mathrm{Ng}, 1990$ [71] & Hong Kong & Mixed & Age, sex, PAH, asbestos & 1419 & Mortality & SMR, silicotic & $2.03(1.35-2.93)$ & 28 \\
\hline 18 & Partanen, 1994 [73] & Finland & Mixed & Age, sex, calendar period & 811 & Incidence & SIR, silicotic & $2.89(2.35-3.48)$ & 190 \\
\hline \multirow[t]{2}{*}{19} & Puntoni, 1988 [105] & Italy & Refractory brick & Age, sex & 231 & Mortality & SMR, silicotic & $1.67(0.61-3.64)$ & 6 \\
\hline & & & & & & Mortality & SMR, non-silicotic & $2.08(0.67-4.84)$ & 5 \\
\hline 20 & Scarselli, 2011 [81] & Italy & Mixed & Age, sex, calendar period & 2034 & Mortality & SMR, silicotic & $1.39(1.17-1.64)$ & 139 \\
\hline 21 & Sherson, 1991 [83] & Denmark & Foundry & Age, sex, calendar period & 6144 & Incidence & SIR, silicotic & $1.71(0.85-3.06)$ & 11 \\
\hline 22 & Tornling, 1991 [88] & Sweden & Ceramic & Age, sex & 280 & Mortality & SMR, silicotic & $2.36(1.07-4.48)$ & 9 \\
\hline 23 & Tse, 2014 [90] & Hong Kong & Mixed & Age, sex, calendar period & 3202 & Mortality & SMR, silicotic & $1.86(1.59-2.17)$ & 157 \\
\hline 24 & Wang, 1996 [96] & China & Metallurgy & Age, sex, calendar period & 4372 & Mortality & SMR, silicotic & $2.37(1.96-2.86)$ & 104 \\
\hline
\end{tabular}


Table 1 Characteristics of silicotic and non-silicotic studies (Continued)

\begin{tabular}{|c|c|c|c|c|c|c|c|c|c|}
\hline 25 & Westerholm, 1980 [9] & Sweden & Mixed & Age, sex, calendar period & 3610 & Mortality & SMR, silicotic & $3.80(2.30-5.80)$ & \\
\hline 26 & Westerholm, 1986 [99] & Sweden & Mixed & Age, sex, calendar period & 712 & Mortality & SMR, silicotic & $5.38(2.20-11.10)$ & 7 \\
\hline 27 & Yu, 2008 [102] & Hong Kong & mixed & Age, calendar period, smoking & 2798 & Mortality & SMR, silicotic & $1.56(0.98-2.63)$ & 86 \\
\hline \multirow[t]{2}{*}{28} & Zambon, 1987 [103] & Italy & Mixed & Age, sex, calendar period & 1313 & Mortality & SMR, silicotic & $2.39(1.86-3.02)$ & 70 \\
\hline & Case-control studies & & & & & & & & \\
\hline 1 & Forastiere, 1989 [45] & Italy & Mixed & Age, sex, calendar period & 595 & Mortality & MOR, silicotic & $2.50(1.20-4.60)$ & 10 \\
\hline 2 & $\mathrm{Fu}, 1994[46]$ & China & Tin mine & Age, sex, smoking & 267 & Incidence & OR, silicotic & $2.03(1.25-3.29)$ & \\
\hline \multirow[t]{2}{*}{3} & Lagorio, 1990 [61] & Italy & Pottery & Age, calendar period, smoking & 391 & Mortality & OR, silicotic & $3.90(1.80-8.30)$ & \\
\hline & & & & & & Mortality & OR, non-silicotic & $1.40(0.70-2.80)$ & \\
\hline 4 & Neuberger, 1988 [70] & Austria & Mixed & Age, sex, calendar period, area, smoking & 2212 & Mortality & MOR, silicotic & $1.41(1.21-1.64)$ & 182 \\
\hline 5 & Schuller, 1986 [82] & Switzerland & Mixed & Calendar period & 2399 & Mortality & MOR, silicotic & $2.23(1.90-2.60)$ & 180 \\
\hline 6 & Tsuda, 2002 [91] & Japan & Mixed & Age, sex, smoking & 501 & Mortality & OR, silicotic & $2.77(1.60-4.77)$ & 184 \\
\hline
\end{tabular}

Cl confidence interval, USA United States of America, PAH polycyclic aromatic hydrocarbons, SMR standardized mortality ratio, SIR standardized incidence ratio $O R$ odds ratio, MOR mortality odds ratio 
plots in Figs. 2, 3 and 4 respectively. Significant betweenstudy heterogeneity was observed in SMR, MOR and SIR studies with $\mathrm{I}^{2}$ of $96 \%, 87 \%$ and $75 \%$ respectively. PMR and OR studies with mortality as outcome showed lower between-study heterogeneity $\left(\mathrm{I}^{2} 62 \%\right.$ and $51 \%$ respectively), which was statistically insignificant ( $p$ value for $\mathrm{Q}$ test $>0.10$ for both). No heterogeneity was observed in the meta-analysis of OR studies with incidence as outcome.
Studies conducted in silicotic subjects yielded a significantly higher pooled SMR of 2.32 (95 \% CI 1.91-2.81) and SIR of 2.49 (95 \% CI 1.87-3.33) as compared to nonsilicotic studies which gave a resulting estimate of 1.78 (95 \% CI 1.07-2.96) for SMR studies and 1.18 (95\% CI 0.86-1.62) for SIR studies. Between-study heterogeneity was statistically significant in silicotic and nonsilicotic studies with SMR as risk measure $\left(\mathrm{I}^{2}=94 \%\right.$

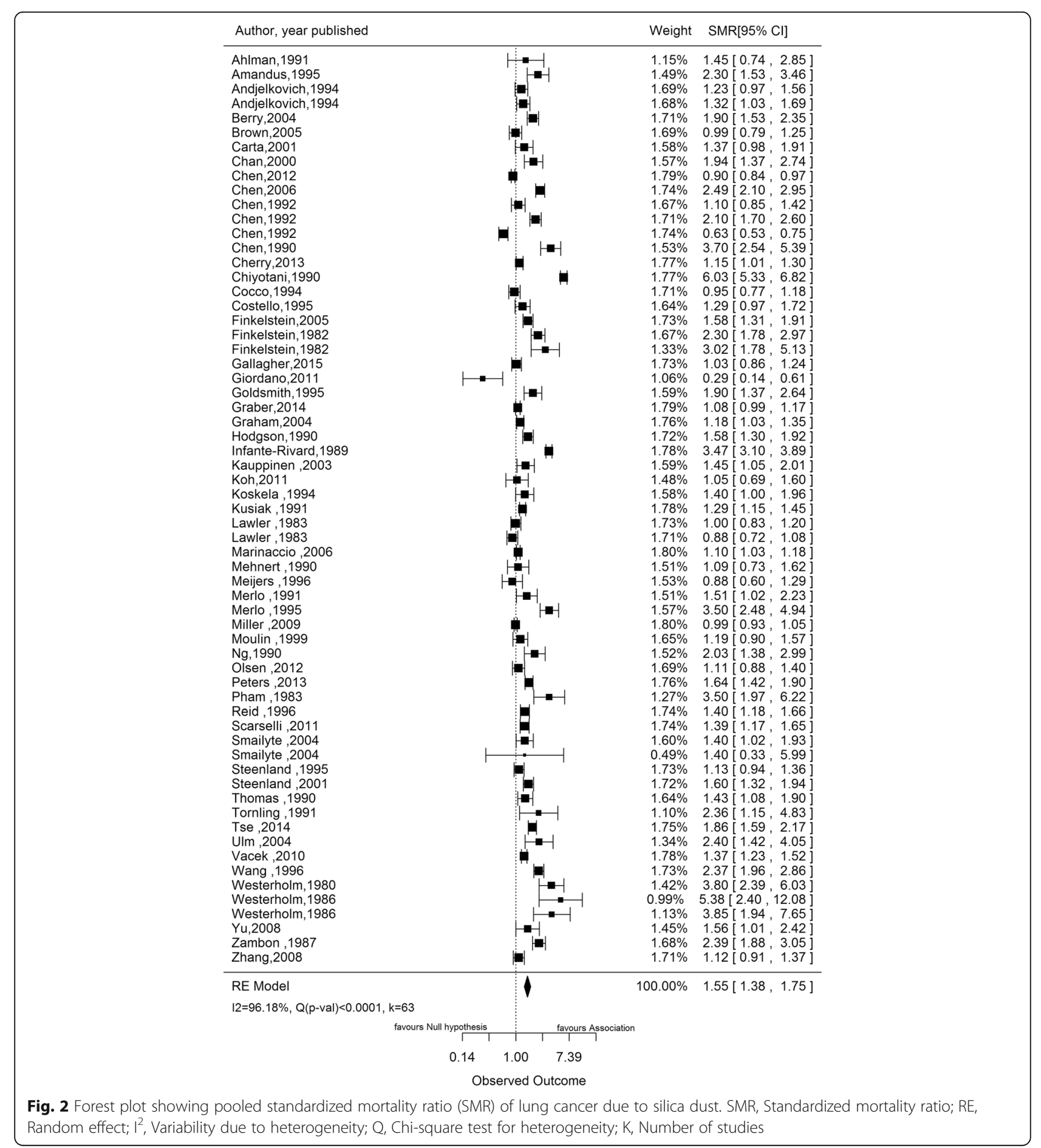




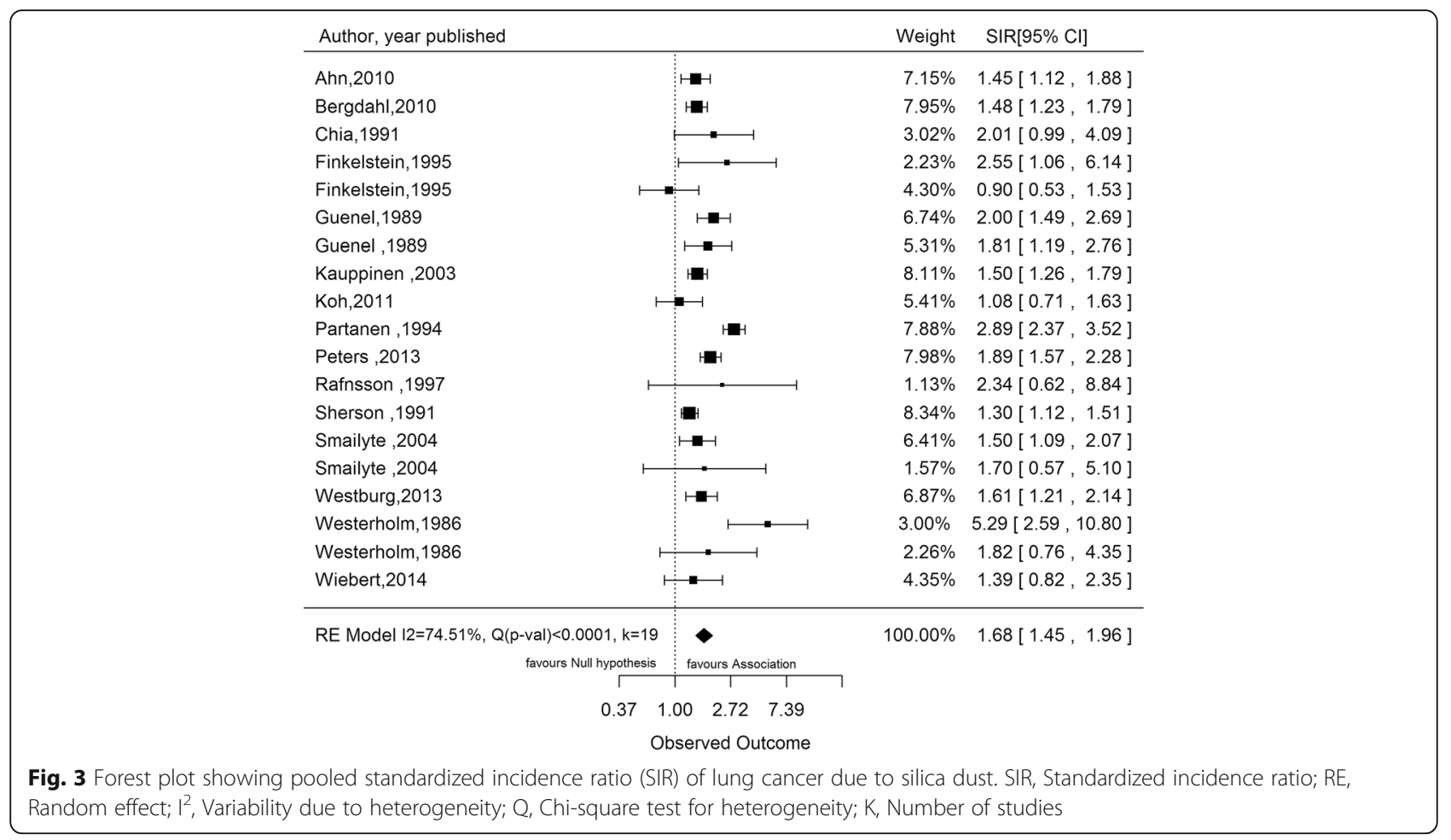

with $p<0.0001$ and $\mathrm{I}^{2}=74 \%$ with $p=0.013$ respectively) but they were found to be lower and statistically insignificant in silicotic and non-silicotic studies with SIR as measure of association $\left(\mathrm{I}^{2}=25 \%\right.$ with $p=0.377$ and $\mathrm{I}^{2}=41 \%$ with $p=0.192)$ respectively.

Subgroup analyses were carried out individually for SMR and SIR studies. We could not perform similar subgroup analysis for the few remaining studies reporting other measures of association due to their limited number. Since the level of between-study heterogeneity was found to be $0 \%$ in the group of OR studies reporting incidence as outcome, we did not perform any further analysis to explore heterogeneity. Subgroup analysis for SMR studies showed a positive association between silica dust exposure and lung cancer in all subgroups except in the subgroup of cement industries which had a pooled risk estimate of 0.87 (95 \% CI $0.42-1.82)$.
Heterogeneity became non-significant $(p>0.10)$ in the subgroups of potteries $\left(\mathrm{I}^{2}=0 \%\right.$ and $\left.p=0.273\right)$, construction industries $\left(\mathrm{I}^{2}=0 \%\right.$ and $\left.\mathrm{p}-0.656\right)$ and in the subgroup including studies done in Australia $\left(\mathrm{I}^{2}=20 \%\right.$ and $p=0.265)$. In all other subgroups, between-study heterogeneity remained significant. Out of 63 SMR studies, only 2 adjusted for smoking $[28,102]$ and the effect measure in this subgroup was 1.83 (95\% CI 1.51-2.22). In the subgroup of studies without adjustment for smoking, the pooled estimate was 1.55 (95\% CI 1.37-1.75). Thirteen SMR studies having none of the other potential occupational carcinogens mentioned in the Methods Section yielded an estimate of 1.32 (95\% CI 1.14-1.54). The positive association between silica and lung cancer became weaker with increasing quality of the included studies, from 2.56 (95 \% CI 1.57-4.19) among SMR studies with an NOS score of $1-3$ to 1.24 (95\% CI

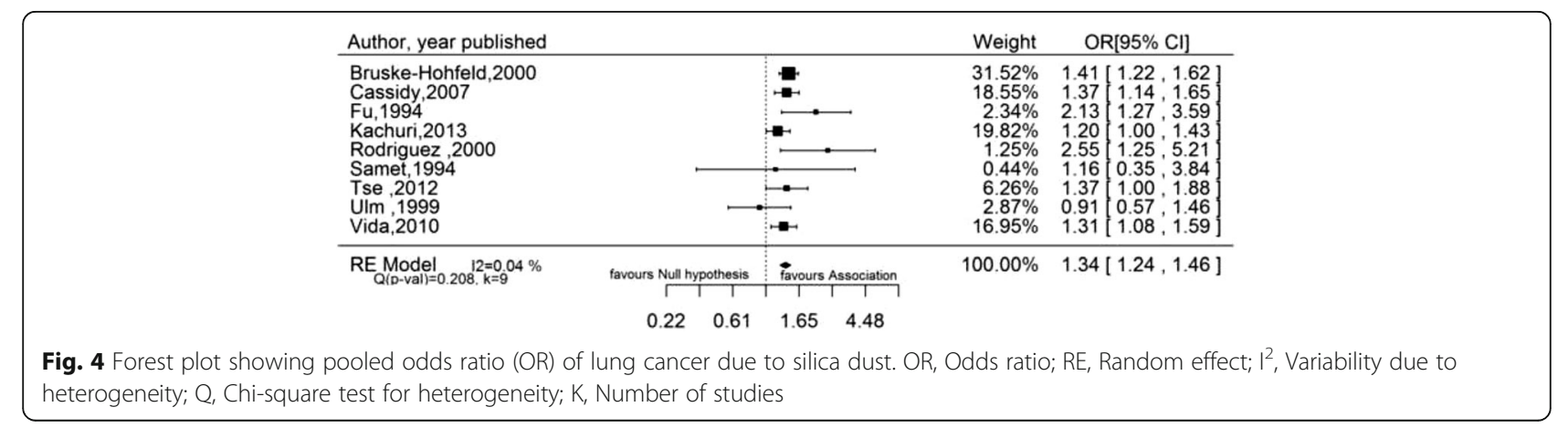


1.01-1.52) in those with an NOS score of 7-9. A similar trend was observed among SIR studies.

Subgroup analysis for SIR studies showed a positive relation between occupational silica exposure and risk of lung cancer in all subgroups, with statistically significant risk estimates in all subgroups except that including studies conducted in Canada $(p=0.494)$. Much of the between-study heterogeneity could be explained by subgrouping the SIR studies and in most of the subgroups, it became statistically insignificant $(p>0.1)$. None of the SIR studies adjusted for smoking. Detailed main statistical analysis, subgroup analyses for SMR and SIR studies and statistical analysis of silicotic and non-silicotic studies are shown in Table 2.

Separate meta-regression analyses were performed for SMR studies, SIR studies and silicotic studies reporting SMR as risk measure. These were done using both univariate and multivariate models. In the univariate metaregression analysis of SMR studies, NOS score was the most important covariate accounting for $19 \%$ of heterogeneity while in the multivariate analysis, the combination of industrial setting, year of publication, geographical location and number of subjects accounted for the maximum amount of heterogeneity $\left(R^{2}=37 \%\right)$. As for the SIR studies, univariate analysis showed that total number of deaths accounted for the highest amount of heterogeneity $\left(\mathrm{R}^{2}=100 \%\right)$ and a combination of number of subjects and NOS score corrected the maximum amount of heterogeneity $\left(R^{2}=15 \%\right)$ in multivariate analysis. Regarding the silicotic studies, the combination of year of publication and total number of deaths corrected $43 \%$ of between-study heterogeneity. Detailed results of meta-regression analyses are shown in Table 3.

For the exposure-response analysis of the relationship between silica dust and risk of lung cancer, reference was made to the subgroup analysis of SMR studies by average level of cumulative silica dust exposure. Nineteen studies were included. It was found that the risk of lung cancer increased with rising exposure level (risk estimate rose from 1.19 (95\% CI 1.02-1.39) in the first quartile to 1.36 (95\% CI $0.87-2.13$ ) in the fourth quartile). However, the $p$ value of the estimate was statistically insignificant for the second, third and fourth quartiles $(p>0.05)$. A high level of between-study heterogeneity was also noted especially with rising quartiles of cumulative silica dust $(p<0.0001)$.

Sensitivity analyses showed that omission of any study did not significantly influence the pooled estimates.

\section{Discussion}

The present meta-analysis, which combines the results from 85 different studies, supports the carcinogenicity of respirable crystalline silica dust on the lung. This positive trend was observed independent of the measure of association and of the level of heterogeneity. The pooled risk estimates in the silicotic studies, which were 2.32 (95 \% CI 1.91-2.81) for SMR studies and 2.49 (95 \% CI 1.87-3.33) for SIR studies, were found to be higher than those in non-silicotic studies, which were 1.78 (95\% CI 1.07-2.96) for SMR studies and 1.18 (95 \% CI 0.86-1.62) for SIR studies. Both silicotic and non-silicotic studies include subjects who are exposed to silica dust. Our results support the hypothesis that silicosis has a stronger association with lung cancer morbidity and mortality than silica exposure on its own. The positive association between silica dust and lung cancer in non-silicotic subjects could probably be due to genetic factors which predispose these individuals to lung cancer with only a minimal exposure to silica dust.

Previous meta-analyses have found a positive association between crystalline silica dust and lung cancer in silicotics and silica-exposed workers, but in non-silicotics, the association was either negative or weakly positive [16, 106-111]. In these published studies, the cohort study subgroups gave pooled estimates ranging from 1.25 (95\% CI 1.18-1.33) to 1.29 (95 \% CI 1.20-1.40) in silica-exposed participants, 1.69 (95\% CI 1.32-2.16) to 2.78 (95 \% CI 2.41-3.22) in silicotics and 1.19 (95\% CI 0.87-1.57) to 1.20 (95\% CI 1.10-1.30) in non-silicotics. The case-control study subgroups yielded risk estimates ranging from 1.41 (95\% CI 1.18-1.70) to 1.42 (95\% CI 1.22-1.65) in silica-exposed workers, 1.70 (95 \% CI 1.15-2.52) to 3.27 (95 \% 1.32-8.20) in silicotics and from 0.97 (95 \% CI 0.68-1.38) to 1.00 (95 \% CI 0.701.30) in non-silicotics [13].

Based on the year of publication, we observed a gradual decline in the pooled risk estimate with time from a pooled SMR of 2.37 (95\% CI 1.76-3.19) and a pooled SIR of 2.32 (95 \% CI 1.50-3.58) in publications before 1991 to a pooled SMR of 1.30 (95 \% CI 1.16-1.46) and a pooled SIR of 1.54 (95\% CI 1.40-1.70) in papers published after 2000. Though some of the papers are updates of older ones, the difference between them is the extended follow-up period in the more recent ones. The lowering risk of lung cancer in recent years may be due to more objective outcome assessment and exposure ascertainment by direct measurement and also due to lower dust concentration as a result of the improvement and stricter implementation of dust control measures.

Our study also showed that the risk of lung cancer differed among various industries. In the SMR studies, the highest pooled risk estimate of 1.48 (95\% CI 1.18-1.86) which was statistically significant was observed in the mining industry. Possible reasons may be due to the higher level of silica exposure and longer duration of time spent in dust-laden environment. In the same subgroup, the lowest risk of lung cancer was observed in the pottery factories with a risk estimate of 1.14 (95 \% CI 1.05-1.23). This may be because clay coatings decrease the biological 
Table 2 Results of meta-analysis of all studies, silicotic studies and non-silicotic studies and subgroup analyses

\begin{tabular}{|c|c|c|c|c|c|c|}
\hline Study design (effect measure) & Number of studies & Effect estimate & $P$ value of effect & $\begin{array}{l}P \text { value of } \\
\text { heterogeneity, Q }\end{array}$ & $P^{2}$ & $P$ value Egger test \\
\hline Cohort studies (SMR) & 63 & $1.55(1.38-1.75)$ & $5.68 \mathrm{E}-13$ & $<0.0001$ & 96.18 & 0.02 \\
\hline Cohort studies (SIR) & 19 & $1.68(1.45-1.96)$ & $1.36 \mathrm{E}-11$ & 4.59E-08 & 74.51 & 0.24 \\
\hline Cohort studies (RR) & 1 & $1.65(1.13-2.40)$ & 0.01 & 1 & & 0.72 \\
\hline Case-control mortality studies (OR) & 5 & $1.82(1.25-2.66)$ & 0.0017 & 0.1070 & 51.17 & 0.51 \\
\hline Case-control incidence studies (OR) & 9 & $1.34(1.24-1.46)$ & $<0.0001$ & 0.2075 & 0 & 0.46 \\
\hline Case-control studies (MOR) & 3 & $1.69(1.26-2.26)$ & $<0.0001$ & $<0.0001$ & 86.70 & 1.00 \\
\hline Proportional mortality studies (PMR) & 2 & $1.10(0.89-1.36)$ & 0.38 & 0.10 & 62.02 & 1.00 \\
\hline Silicotic studies (SMR) & 24 & $2.32(1.91-2.81)$ & $<0.0001$ & $<0.0001$ & 94.34 & - \\
\hline Silicotic studies (SIR) & 4 & $2.49(1.87-3.33)$ & $<0.0001$ & 0.377 & 25.04 & - \\
\hline Silicotic studies (OR) & 3 & $2.56(1.84-3.57)$ & $<0.0001$ & 0.345 & 2.65 & - \\
\hline Silicotic studies (MOR) & 3 & $1.88(1.31-2.71)$ & 0.0006 & $<0.0001$ & 86.98 & - \\
\hline Non-silicotic studies (SMR) & 4 & $1.78(1.07-2.96)$ & 0.027 & 0.013 & 74.37 & - \\
\hline Non-silicotic studies (SIR) & 2 & $1.18(0.86-1.62)$ & 0.292 & 0.192 & 41.21 & - \\
\hline \multicolumn{7}{|l|}{ Subgroup analysis of SMR studies } \\
\hline \multicolumn{7}{|l|}{ Year of publication } \\
\hline$\leq 1990$ & 16 & $2.37(1.76-3.19)$ & $1.24 \mathrm{E}-08$ & $2.92 \mathrm{E}-94$ & 95.58 & 0.35 \\
\hline $1991-2000$ & 21 & $1.44(1.21-1.71)$ & 2.97E-05 & $1.25 \mathrm{E}-30$ & 89.89 & 0.16 \\
\hline$>2000$ & 26 & $1.30(1.16-1.46)$ & 1.05E-05 & $9.98 \mathrm{E}-49$ & 93.50 & 0.60 \\
\hline \multicolumn{7}{|l|}{ Industry } \\
\hline Mine & 18 & $1.48(1.18-1.86)$ & 0.00 & $4.73 \mathrm{E}-59$ & 97.17 & 0.18 \\
\hline Foundry & 4 & $1.51(0.99-2.29)$ & 0.05 & 0.02 & 86.53 & 0.75 \\
\hline Pottery & 7 & $1.14(1.05-1.23)$ & 0.00 & 0.27 & 0.02 & 1.00 \\
\hline Cement & 4 & $0.87(0.42-1.82)$ & 0.71 & $<0.0001$ & 84.87 & 0.75 \\
\hline Construction & 2 & $1.55(1.31-1.82)$ & $1.94 \mathrm{E}-07$ & 0.66 & 0.00 & 1.00 \\
\hline Stone \& granite & 8 & $1.32(1.15-1.50)$ & $6.24 \mathrm{E}-05$ & 0.01 & 65.17 & 0.72 \\
\hline Mixed & 19 & $2.03(1.61-2.56)$ & $1.68 \mathrm{E}-09$ & & 96.95 & 0.73 \\
\hline \multicolumn{7}{|l|}{ Country } \\
\hline Europe & 26 & $1.54(1.25-1.89)$ & 4.95E-05 & 4.09E-33 & 95.70 & 0.13 \\
\hline USA & 15 & $1.24(1.12-1.38)$ & $6.24 \mathrm{E}-05$ & $5.32 \mathrm{E}-07$ & 79.80 & 0.06 \\
\hline Canada & 5 & $2.14(1.46-3.13)$ & $9.27 \mathrm{E}-05$ & $2.34 \mathrm{E}-32$ & 95.70 & 0.82 \\
\hline Australia & 2 & $1.73(1.51-1.98)$ & 7.65E-15 & 0.26 & 19.61 & 1.00 \\
\hline Asia & 14 & $1.74(1.27-2.39)$ & $<0.0001$ & & 97.56 & 0.75 \\
\hline \multicolumn{7}{|l|}{ Occupational confounders } \\
\hline Absent & 13 & $1.32(1.14-1.54)$ & $<0.0001$ & $1.79 \mathrm{E}-13$ & 87.15 & 0.06 \\
\hline Present & 30 & $1.35(1.17-1.57)$ & $7.28 \mathrm{E}-05$ & 7.37E-55 & 94.47 & 0.55 \\
\hline \multicolumn{7}{|l|}{ Reported measure adjusted for smoking } \\
\hline Not adjusted & 61 & $1.55(1.37-1.75)$ & 4.16E-12 & & 96.37 & 0.02 \\
\hline Adjusted & 2 & $1.83(1.51-2.22)$ & $7.23 \mathrm{E}-10$ & 0.43 & 0.00 & 1.00 \\
\hline \multicolumn{7}{|l|}{ NOS score } \\
\hline $1-3$ & 6 & $2.56(1.57-4.19)$ & 0.00 & $2.35 \mathrm{E}-65$ & 96.18 & 1.00 \\
\hline $4-6$ & 35 & $1.57(1.36-1.82)$ & $9.02 \mathrm{E}-10$ & $1.68 \mathrm{E}-80$ & 93.07 & 0.45 \\
\hline $7-9$ & 15 & $1.24(1.01-1.52)$ & 0.042025 & $1.56 \mathrm{E}-44$ & 97.23 & 0.17 \\
\hline
\end{tabular}


Table 2 Results of meta-analysis of all studies, silicotic studies and non-silicotic studies and subgroup analyses (Continued)

\begin{tabular}{|c|c|c|c|c|c|c|}
\hline \multicolumn{7}{|c|}{ Cumulative Silica Dust Exposure (CSDE) (mg/m³ years) } \\
\hline $0<\mathrm{CSDE} \leq 0.83$ & 5 & $1.19(1.02-1.39)$ & 0.02 & 0.02 & 68.92 & 0.23 \\
\hline $0.83<\mathrm{CSDE} \leq 3.9$ & 5 & $1.27(0.89-1.82)$ & 0.19 & 1.04E-24 & 97.57 & 0.48 \\
\hline $3.9<\mathrm{CSDE} \leq 8.35$ & 4 & $1.33(0.94-1.87)$ & 0.10 & 2.97E-10 & 91.94 & 0.75 \\
\hline $\operatorname{CSDE}>8.35$ & 5 & $1.36(0.87-2.13)$ & 0.18 & 1.15E-21 & 96.33 & 0.82 \\
\hline \multicolumn{7}{|c|}{ Subgroup analysis of SIR studies } \\
\hline \multicolumn{7}{|l|}{ Year of publication } \\
\hline$\leq 1990$ & 4 & $2.32(1.50-3.58)$ & $<0.0001$ & 0.07 & 64.63 & 0.75 \\
\hline $1991-2000$ & 6 & $1.77(1.17-2.69)$ & 0.01 & 5.07E-09 & 85.81 & 0.47 \\
\hline$>2000$ & 9 & $1.54(1.40-1.70)$ & $8.29 \mathrm{E}-18$ & 0.41 & 17.30 & 1.00 \\
\hline \multicolumn{7}{|l|}{ Industry } \\
\hline Mine & 2 & $1.67(1.32-2.13)$ & $2.55 \mathrm{E}-05$ & 0.07 & 69.32 & 1.00 \\
\hline Foundry & 4 & $1.40(1.23-1.58)$ & 2.67E-07 & 0.52 & 7.15 & 0.33 \\
\hline Pottery & 1 & $2.34(0.62-8.84)$ & 0.21 & 1 & & 0.33 \\
\hline Cement & 3 & $1.34(1.01-1.76)$ & 0.04 & 0.43 & 12.61 & 1.00 \\
\hline Construction & 1 & $1.50(1.26-1.79)$ & $5.04 \mathrm{E}-06$ & 1 & & 1.00 \\
\hline Granite & 3 & $1.94(1.55-2.44)$ & $1.33 \mathrm{E}-08$ & 0.93 & 0.00 & 1.00 \\
\hline Mixed & 5 & $2.13(1.18-3.87)$ & 0.01 & 4.08E-05 & 85.96 & 0.82 \\
\hline \multicolumn{7}{|l|}{ Country } \\
\hline Europe & 13 & $1.78(1.48-2.14)$ & 1.16E-09 & $9.18 \mathrm{E}-08$ & 77.40 & 0.13 \\
\hline Canada & 2 & $1.42(0.52-3.93)$ & 0.49 & 0.05 & 74.77 & 1.00 \\
\hline Australia & 1 & $1.89(1.57-2.28)$ & $2.26 \mathrm{E}-11$ & 1 & & 1.00 \\
\hline Asia & 3 & $1.38(1.10-1.73)$ & $<0.0001$ & 0.28 & 6.72 & 1.00 \\
\hline \multicolumn{7}{|c|}{ Occupational confounders } \\
\hline Absent & 3 & $1.94(1.55-2.44)$ & 1.33E-08 & 0.93 & 0.00 & 1.00 \\
\hline Present & 12 & $1.57(1.32-1.87)$ & 4.14E-07 & 4.45E-08 & 80.28 & 0.64 \\
\hline \multicolumn{7}{|l|}{ NOS grading } \\
\hline $1-3$ & 3 & $1.99(1.19-3.30)$ & 0.01 & 0.95 & 0.00 & 1.00 \\
\hline $4-6$ & 11 & $1.55(1.28-1.87)$ & $5.74 \mathrm{E}-06$ & 2.36E-08 & 82.02 & 0.76 \\
\hline $7-9$ & 1 & $1.61(1.21-2.14)$ & $<0.001$ & 1 & & 0.76 \\
\hline
\end{tabular}

$P^{2}$ variability due to heterogeneity; $R^{2}, S M R$ standardized mortality ratio, $S I R$ standardized incidence ratio $O R$ odds ratio, MOR mortality odds ratio, $P M R$ proportional mortality ratio, NOS Newcastle-Ottawa scale

availability of the toxic crystalline silica surfaces, thereby diminishing or deferring the disease risk. Harrison et al. found that the percentage of clay coating silica particles was $45 \%$ in pottery worksites, $18 \%$ in tin mines and $13 \%$ in tungsten mines [112]. Studies have shown that clay and aluminum oxide or aluminosilicate surface coatings of respirable crystalline silica particle surfaces can modify the cytotoxic and fibrogenic activities of crystalline silica dust [113]. A negative association, with a risk estimate of 0.87 (95\% CI 0.42-1.82), without statistical significance $(p=0.714)$ was observed between cement dust exposure and lung cancer mortality in cement factory workers in this meta-analysis. A reverse trend was observed among SIR studies in the subgroup of cement industries. Possible explanations could be that cement dust is weakly carcinogenic and cement factory workers are immediately removed from the high-risk job as soon as they are diagnosed with any respiratory problems, thereby decreasing the chance of progress to more severe disease and mortality.

When conducting a meta-analysis of epidemiological studies, significant heterogeneity in risk across studies reflects differences in workplace exposures, assessment of exposure, data collection processes, population being studied and, in the case of silica, in the biological activity of the silica particles. It has been suggested that a variable biological activity of silica particulates might be related to particle size, time since fracture and presence of other minerals or dust components that might cover the silenol radicals on the surface of the silica particles 
Table 3 Results of meta-regression analyses

\begin{tabular}{|c|c|c|c|c|c|c|c|c|}
\hline Measure & Parameter & k & Estimate & $P$ value estimate & $P$ value of $Q$ & $1^{2}$ & $R^{2}$ & $p$ covariate \\
\hline \multicolumn{9}{|c|}{ Meta-regression analysis of SMR studies } \\
\hline SMR & No covariate & 63 & $1.55(1.38-1.75)$ & $<0.0001$ & $<0.0001$ & 96.18 & & \\
\hline \multirow[t]{6}{*}{ Univariate model } & Year of publication & 63 & $2.30 E+18(2.41 E+08-2.19 E+28)$ & 0.003 & $<0.0001$ & 95.44 & 15.12 & 0.000 \\
\hline & Industry & 63 & $1.15(0.86-1.53)$ & 0.353 & $<0.0001$ & 95.71 & 8.15 & 0.027 \\
\hline & Person-years of follow-up & 22 & $1.53(1.25-1.87)$ & $<0.0001$ & $<0.0001$ & 94.73 & 13.4 & 0.050 \\
\hline & NOS score & 63 & $3.53(2.27-5.49)$ & $<0.0001$ & $<0.0001$ & 95.11 & 19.18 & 0.000 \\
\hline & Number of subjects & 63 & $1.69(1.48-1.92)$ & $<0.0001$ & $<0.0001$ & 95.43 & 10.89 & 0.008 \\
\hline & Total number of deaths & 54 & $1.69(1.48-1.94)$ & $<0.0001$ & $<0.0001$ & 95.31 & 13.94 & 0.006 \\
\hline \multirow[t]{10}{*}{ Multivariate model } & Industry, year of publication & 63 & $1.07 E+19(3.85 E+09-2.97 E+28)$ & $<0.0001$ & $<0.0001$ & 94.65 & 25.51 & $<0.0001$ \\
\hline & Industry, year of publication, geographical location & 63 & $1.04 E+20(4.90 E+10-2.21 E+29)$ & $<0.0001$ & $<0.0001$ & 94.3 & 28.85 & $<0.0001$ \\
\hline & $\begin{array}{l}\text { Industry, year of publication, geographical location, } \\
\text { number of subjects }\end{array}$ & 63 & $1.80 E+17(1.67 E+08-1.94 E+26)$ & $<0.0001$ & $<0.0001$ & 93.18 & 37.41 & $<0.0001$ \\
\hline & $\begin{array}{l}\text { Industry, year of publication, geographical location, } \\
\text { number of subjects, NOS score }\end{array}$ & 63 & $1.06 E+16(5.27 E+06-2.12 E+25)$ & 0.001 & $<0.0001$ & 93.05 & 37.04 & $<0.0001$ \\
\hline & $\begin{array}{l}\text { Industry, year of publication, geographical location, } \\
\text { number of subjects, total deaths }\end{array}$ & 54 & $5.32 E+18(1.07 E+08-2.65 E+29)$ & 0.001 & $<0.0001$ & 92.72 & 34.76 & $<0.0001$ \\
\hline & $\begin{array}{l}\text { Industry, year of publication, geographical location, } \\
\text { NOS score }\end{array}$ & 63 & $1.29 E+17(3.61 E+07-4.61 E+26)$ & $<0.0001$ & $<0.0001$ & 93.77 & 32.23 & $<0.0001$ \\
\hline & Person-years of follow-up, industry & 22 & $1.22(0.76-1.96)$ & 0.408 & $<0.0001$ & 94.12 & 13.87 & 0.086 \\
\hline & Person-years of follow-up, industry, year of publication & 22 & $2.80 E+14(2.88 E-08-2.73 E+36)$ & 0.198 & $<0.0001$ & 92.81 & 17.99 & 0.079 \\
\hline & $\begin{array}{l}\text { Person-years of follow-up, industry, year of publication, } \\
\text { geographical location }\end{array}$ & 22 & $1.55 E+23(4.66 E-02-5.12 E+47)$ & 0.064 & $<0.0001$ & 92.31 & 23.08 & 0.056 \\
\hline & Person-years of follow-up, number of subjects & 22 & $1.62(1.31-2.00)$ & $<0.0001$ & $<0.0001$ & 92.9 & 17.36 & 0.055 \\
\hline \multicolumn{9}{|c|}{ Meta-regression analysis of SIR studies } \\
\hline SIR & No covariate & 19 & $1.68(1.45-1.96)$ & $<0.0001$ & $<0.0001$ & 74.51 & & \\
\hline \multirow[t]{4}{*}{ Univariate model } & Year of publication & 19 & $7.92 \mathrm{E}+11(3.71 \mathrm{E}-02-1.69 \mathrm{E}+25)$ & 0.080 & $<0.0001$ & 72.31 & 4.27 & 0.086 \\
\hline & Industry & 19 & $1.37(0.97-1.95)$ & 0.077 & $<0.0001$ & 70.88 & 11.68 & 0.214 \\
\hline & Number of subjects & 19 & $1.88(1.55-2.28)$ & $<0.0001$ & $<0.0001$ & 69.94 & 18.16 & 0.086 \\
\hline & Total number of deaths & 5 & $1.29(1.05-1.59)$ & 0.017 & 0.687 & 0 & 100 & 0.017 \\
\hline \multirow[t]{3}{*}{ Multivariate model } & Number of subjects, exposure level & 19 & $2.09(1.47-2.96)$ & $<0.0001$ & $<0.0001$ & 72.12 & 9.02 & 0.197 \\
\hline & Number of subjects, NOS score & 19 & $3.01(1.52-5.95)$ & 0.002 & $<0.0001$ & 69.36 & 15.16 & 0.087 \\
\hline & Number of subjects, industry & 19 & $1.71(1.03-2.85)$ & 0.037 & $<0.0001$ & 70.28 & 10.84 & 0.229 \\
\hline
\end{tabular}


Table 3 Results of meta-regression analyses (Continued)

\begin{tabular}{|c|c|c|c|c|c|c|c|c|}
\hline \multicolumn{9}{|c|}{ Meta- regression of silicotic studies } \\
\hline \multirow[t]{6}{*}{ SMR } & Year of publication & 24 & 7.03E $+21(5.05 E+04-9.79 E+38)$ & 0.013 & $<0.0001$ & 92.23 & 20.55 & 0.014 \\
\hline & Year of publication, total number of deaths & 20 & $1.59 E+23(1.60 E+05-1.57 E+41)$ & 0.012 & $<0.0001$ & 86.98 & 42.87 & 0.002 \\
\hline & $\begin{array}{l}\text { Year of publication, total number of deaths, geographical } \\
\text { location, industry }\end{array}$ & 20 & $4.61 E+22(2.40 E+03-8.85 E+41)$ & 0.021 & $<0.0001$ & 86.9 & 33.84 & 0.022 \\
\hline & Year of publication, total number of deaths, industry & 20 & $6.07 E+22(1.43 E+04-2.58 E+41)$ & 0.017 & $<0.0001$ & 87.46 & 38.8 & 0.002 \\
\hline & $\begin{array}{l}\text { Year of publication, total number of deaths, geographical } \\
\text { location }\end{array}$ & 20 & $9.89 E+22(2.24 E+04-4.37 E+41)$ & 0.016 & $<0.0001$ & 86.65 & 38.3 & 0.007 \\
\hline & Year of publication, geographical location & 24 & $1.26 E+22(3.90 E+04-4.08 E+39)$ & 0.013 & $<0.0001$ & 92.05 & 16.98 & 0.050 \\
\hline
\end{tabular}

$k$ number of studies, $Q$ chi-square test for heterogeneity, $I^{2}$ variability due to heterogeneity, $R^{2}$ amount of heterogeneity accounted for, $S M R$ standardized mortality ratio, $S I R$ standardized incidence ratio, NOS Newcastle-Ottawa scale 
[114]. We were able to explore sources of heterogeneity to varying extent in our study through meta-regression analysis (up to $100 \%$ heterogeneity could be corrected when total number of deaths was used as covariate in the univariate analysis of SIR studies). Higgins commented that heterogeneity is an inevitable part of a meta-analysis and that any amount of heterogeneity is acceptable, provided the predefined eligibility criteria for the metaanalysis are sound and the data are correct, both of which have been duly verified in this study [18].

The exposure-response analysis showed that the higher the level of cumulative silica dust exposure, the more is the risk of lung cancer. However, the high level of heterogeneity limits any inference of causality. Wrong estimation of the level and duration of exposure of workers, varying measurement methods and incorrect data collection may lead to significant between-study heterogeneity in the determination of an exposureresponse relationship. Similar findings were obtained in the dose-response meta-analysis of silica and lung cancer using 4 cohort and 6 case-control studies performed by Lacasse et al. [16].

The first strength of our meta-analysis is that we have tried to include the maximum number of relevant studies published till date. The number and variety of studies included in a meta-analysis are sometimes reduced to increase the homogeneity of the studies evaluated. However, this potentially reduces the amount of information on factors that influence the outcome of individual studies. To our knowledge, our meta-analysis is the largest one conducted on this topic. Secondly, we conformed to the PRISMA guidelines for a systematic and objective data analysis. Thirdly, subgroup and meta-regression analyses have allowed us to explore in more detail the issue of heterogeneity which, as expected was substantially high. Fourthly, we have been able to explore the exposure-response relationship between occupational exposure to silica dust and risk of lung cancer.

Two main limitations of our study should be noted. First is the ensuing risk of bias of the included studies. Although publication bias was not detected from funnel plots and by Egger's regression test of OR and SIR studies, it was found to be significant $(p<0.05)$ for SMR studies. The most important factors that can account for confounding bias in the interpretation of the results are cigarette smoking and occupational carcinogens including radon, arsenic, $\mathrm{PAH}$, diesel, talc, cadmium and asbestiform fibers. When we compared the pooled risk estimate of smoking-adjusted SMR studies with that of the unadjusted studies, we found that cigarette smoking does not account for increased risk of lung cancer among silica-exposed workers. We obtained similar results by subdividing SMR studies into those with potential exposure to occupational confounders and those excluding their presence. These findings imply that the presence of other potential lung carcinogens in silicaexposed jobs does not suggest a confounding effect on the positive relationship between silica and lung cancer. Observational studies are also prone to biases due to selection of study population and loss to follow-up. It is, however difficult to completely control or eliminate all bias when designing or performing an observational study [115]. Our meta-analysis has made an attempt to address this limitation by conducting subgroup analysis based on NOS score. We found that the lower-quality studies tend to overestimate the effect measure, probably due to reliance on self-reporting rather than objective assessment of outcome and indirect methods of measurement of past exposure to silica dust among workers. Self-reporting are usually subject to recall bias leading to exposure and outcome misclassification and overestimation of risk estimates. Second drawback is the high degree of between-study heterogeneity noted except in the group of case-control studies with incidence as outcome.

We have shown, through this meta-analysis that the risk of lung cancer is higher in workers exposed to crystalline silica dust but the exact mechanism of carcinogenicity in human beings are yet to be determined. Three mechanisms have been proposed based on experimental studies in animals. First, exposure to crystalline silica impairs alveolar-macrophage-mediated particle clearance thereby increasing persistence of silica in the lungs, which results in macrophage activation, and the sustained release of chemokines and cytokines. In rats, persistent inflammation is characterized by neutrophils that generate oxidants that induce genotoxicity, injury and proliferation of lung epithelial cells leading to the development of lung cancer. Second, extracellular generation of free radicals by crystalline silica depletes antioxidants in the lung-lining fluid. Third, crystalline silica particles are taken up by epithelial cells followed by intracellular generation of free radicals that directly induce genotoxicity. The IARC considers the first mechanism as the most prominent based on the current experimental data using inhalation or intratracheal instillation in rats, although the other mechanisms cannot be excluded. More research has been recommended in this particular field [13].

\section{Conclusion}

To conclude, this paper supports the positive association of crystalline silica and lung cancer and the existence of an exposure-response relationship between these two, with a high degree of heterogeneity in the analyses. The risk tends to be more pronounced in the presence of silicosis and in the mining industry and is not significantly affected by the presence or exclusion of occupational 
confounding factors or by adjustment for cigarette smoking. A gradual reduction in the risk with time has also been noted. Further research is needed to find out whether non-silicotics are truly at risk, whether a predisposing factor would explain this potential risk and to determine the mechanism of carcinogenicity of silica in humans.

\section{Additional files}

Additional file 1: Search strategy for Medline database. (DOC 36 kb)

Additional file 2: Characteristics of all studies included. (DOC $232 \mathrm{~kb}$ )

Additional file $\mathbf{3}$ Newcastle-Ottawa Scale (NOS) score for cohort and case-control studies. (DOC $141 \mathrm{~kb}$ )

Additional file 4: Funnel plot for studies with standardized mortality ratio (SMR) as measure of association. (DOC $107 \mathrm{~kb}$ )

Additional file 5: Funnel plot for studies with standardized incidence ratio (SIR) as measure of association. (DOC $109 \mathrm{~kb}$ )

Additional file 6: Funnel plot for studies with odds ratio (OR) as measure of association. (DOC $144 \mathrm{~kb}$ )

\section{Abbreviations}

Cl: Confidence interval; IARC: International Agency for Research on Cancer; MOR: Mortality odds ratio; NOS: Newcastle-Ottawa scale; OR: Odds ratio PAH: Polycyclic aromatic hydrocarbons; PMR: Proportional mortality ratio; PRISMA: Preferred reporting items for systematic reviews and meta-analyses; SE: Standard error; SIR: Standardized incidence ratio; SMR: Standardized mortality ratio

\section{Acknowledgments}

The authors are grateful to Dr Naresh Rughooputh for his advice on data analysis and manuscript revision and to Dr Yuanchao Song for his valuable assistance in literature search.

\section{Funding}

This work was financially supported by grants from the National Natural Scientific Foundation of China (81372967) and from the National Environmental Protection Public Welfare Industry Targeted Research Fund (201309046).

\section{Availability of data and materials}

All data and materials are available within the main manuscript and additional files.

\section{Authors' contributions}

The requirements of authorship were met by all authors. SPR and WC conceived the idea of the study. SPR, MSR, YG, YR and WC were involved in study design, selection of studies, extraction and interpretation of data, statistical analysis and writing of the manuscript. All authors have read and approved the final version of the manuscript for submission to your journal.

\section{Competing interests}

The authors declare that they have no competing interests.

\section{Consent for publication}

Not applicable.

\section{Ethics approval and consent to participate}

Not applicable.

\section{Author details}

'Department of Occupational \& Environmental Health, School of Public Health, Tongji Medical College, Huazhong University of Science and Technology, Wuhan, Hubei 430030, China. ${ }^{2}$ Key Laboratory of Environment and Health, Ministry of Education \& Ministry of Environmental Protection, and State Key Laboratory of Environmental Health (Incubating), School of Public Health, Tongji Medical College, Huazhong University of Science and Technology, Wuhan, Hubei 430030, China. ${ }^{3}$ Department of Nephrology,
Tongji Hospital, Tongji Medical College, Huazhong University of Science and Technology, Wuhan, Hubei 430030, China.

Received: 30 November 2015 Accepted: 21 October 2016

Published online: 04 November 2016

References

1. Ministry of Health of the People's Republic of China. Chinese annual health statistical report in 2009. Beijing: Ministry of Health of the People's Republic of China; 2009.

2. World Health Organization Global Occupational Health Network. Elimination of silicosis. GOHNET Newsletter 12. Geneva: World Health Organization Global Occupational Health Network; 2007.

3. Kauppinen T, Toikkanen J, Pedersen D, Young R, Ahrens W, Boffetta P, et al. Occupational exposure to carcinogens in the European Union. Occup Environ Med. 2000;57(1):10-8.

4. US National Institute for Occupational Safety and Health. Health effects of occupational exposure to respirable crystalline silica. Washington: US Department of Health and Human Services; 2002.

5. Small C, Naumann T. Holocene volcanism and the global distribution of human population. Environ Hazards. 2001;3:93-109.

6. Molocznik A. Qualitative and quantitative analysis of agricultural dust in working environment. Ann Agric Environ Med. 2002;9(1):71-8

7. Leung CC, Yu IT, Chen W. Silicosis. Lancet. 2012;379(9830):2008-18.

8. Westerholm P. Silicosis. Observations on a case register. Scand J Work Environ Health. 1980;6 Suppl 2:1-86.

9. Finkelstein M, Kusiak R, Suranyi G. Mortality among miners receiving workmen's compensation for silicosis in Ontario: 1940-1975. J Occup Med. 1982;24(9):663-7.

10. Goldsmith DF, Guidotti TL, Johnston DR. Does occupational exposure to silica cause lung cancer? Am J Ind Med. 1982:3(4):423-40.

11. Goldsmith DF, Winn DM, Shy CM. Silica, silicosis and lung cancer. Controversy in occupational medicine. New York: Praeger publications; 1986

12. International Agency for Research on Cancer. Monographs on the evaluation of carcinogenic risks to humans. Vol. 68: Silica, some silicates, coal dust and para-aramid fibrils. Lyon: International Agency for Research on Cancer; 1997.

13. International Agency for Research on Cancer. Monographs on the evaluation of carcinogenic risks to humans. Vol. 100C: metals, particles and fibers. Lyon: International Agency for Research on Cancer; 2012.

14. Moher D, Liberati A, Tetzlaff J, Altman DG. Preferred reporting items for systematic reviews and meta-analyses: the PRISMA Statement. Open Med. 2009:3(3):123-30

15. Wells GA, Shea B, O'Connell D, Peterson J, Welch V, Losos M, et al. The Newcastle-Ottawa Scale (NOS) for assessing the quality of non-randomized studies in meta-analyses. 2011. http://www.ohri.ca/programs/clinical_ epidemiology/oxford.htm. Accessed 4 May 2016.

16. Lacasse Y, Martin S, Simard S, Desmeules M. Meta-analysis of silicosis and lung cancer. Scand J Work Environ Health. 2005:31(6):450-8.

17. Higgins JP, Thompson SG. Quantifying heterogeneity in a meta-analysis. Stat Med. 2002:21(11):1539-58.

18. Higgins JPT, Green S. Cochrane Handbook for Systematic Reviews of Interventions version 5.1.0. 2011.

19. Hosmer DW Jr, Lemeshow S, Sturdivant RX. Applied logistic regression. 3rd ed. New York: Wiley; 2013.

20. Egger M, Davey Smith G, Schneider M, Minder C. Bias in meta-analysis detected by a simple graphical test. BMJ. 1997;315(7109):629-34.

21. Cran.r-project.org [Internet]. The comprehensive R archive network Available at: http://cran.r-project.org/. Accessed 30 Oct 2015.

22. Metafor-project.org [Internet]. The metafor Package: A Meta-Analysis Package for R Last modified: 2015/05/08 08:19 by Wolfgang Viechtbauer. Available at: http://www.metafor-project.org/. Accessed 30 Oct 2015.

23. Ahlman K, Koskela RS, Kuikka P, Koponen M, Annanmaki M. Mortality among sulphide ore miners. Am J Ind Med. 1991;19(5):603-17.

24. Ahn YS, Won JU, Park RM. Cancer morbidity of foundry workers in Korea. J Korean Med Sci. 2010;25(12):1733-41.

25. Amandus HE, Shy C, Castellan RM, Blair A, Heineman EF. Silicosis and lung cancer among workers in North Carolina dust trades. Scand J Work Environ Health. 1995:21 Suppl 2:81-3.

26. Andjelkovich DA, Shy CM, Brown MH, Janszen DB, Levine RJ, Richardson RB. Mortality of iron foundry workers.III. Lung cancer case-control study. J Occup Med. 1994;36(12):1301-9. 
27. Bergdahl IA, Jonsson $H$, Eriksson $K$, Damber $L$, Jarvholm B. Lung cancer and exposure to quartz and diesel exhaust in Swedish iron ore moners with concurrent exposure to radon. Occup Environ Med. 2010;67(8):513-8.

28. Berry G, Rogers A, Yeung P. Silicosis and lung cancer: a mortality study of compensated men with silicosis in New South Wales, Australia. Occup Med (Lond). 2004;54(6):387-94.

29. Brown TP, Rushton L. Mortality in the UK industrial silica sand industry: I. Assessment of exposure to respirable crystalline silica. Occup Environ Med. 2005;62(7):442-5.

30. Bruske-Hohlfeld I, Mohner M, Pohlabeln H, et al. Occupational lung cancer risk for men in Germany: results from a pooled case-control study. Am J Epidemiol. 2000;151:384-95.

31. Carta P, Aru G, Manca P. Mortality from lung cancer among silicotic patients in Sardinia: an update study with 10 more years of follow-up. Occup Environ Med. 2001;58(12):786-93.

32. Cassidy A, Mannetje A, Van Tongeren M, Field JK, Zaridze D, SzeszeniaDabrowska $N$, et al. Occupational exposure to crystalline silica and risk of lung cancer: a multicenter case-control study in Europe. Epidemiology. 2007;18(1):36-43.

33. Chan CK, Leung CC, Tam CM, Yu TS, Wong TW. Lung cancer mortality among a cohort of men in a silicotic register. J Occup Env Med. 2000;42(1):69-75.

34. Chen J, McLaughlin JK, Zhang JY, Stone BJ, Luo J, Chen RA, et al. Mortality among dust-exposed Chinese mine and pottery workers. J Occup Med. 1992;34(3):311-6.

35. Chen SY, Hayes RB, Liang SR, Li QG, Stewart PA, Blair A. Mortality experience of haematite mine workers in China. Br J Ind Med. 1990;47(3):175-81.

36. Chen W, Liu Y, Wang H, Hnizdo E, Sun Y, Su L, et al. Long-term exposure to silica dust and risk of total and cause-specific mortality in Chinese workers: a cohort study. PLoS Med. 2012;9(4):e1001206.

37. Chen W, Yang J, Chen J, Bruch J. Exposure to silica mixed dust and cohort mortality study in tin mines: exposure-response analysis and risk assessment of lung cancer. Am J Ind Med. 2006;49(2):67-76.

38. Cherry N, Harris J, McDonald C, Turner S, Taylor TN, Cullinan P. Mortality in a cohort of Staffordshire pottery workers: follow-up to December 2008. Occup Environ Med. 2013;70(3):149-55.

39. Chia SE, Chia KS, Phoon WH, Lee HP. Silicosis and lung cancer among Chinese granite workers. Scand J Work Environ Health. 1991;17(3):170-4.

40. Chiyotani K, Saito K, Okubo T, Takahashi K. Lung cancer risk among pneumoconiosis patients in Japan with special reference to silicotics. IARC Sci Publ. 1990;97:95-104.

41. Cocco PL, Carta P, Belli S, Picchiri GF, Flore MV. Mortality of Sardinian lead and zinc miners: 1960-88. Occup Environ Med. 1994;51(10):674-82.

42. Costello J, Castellan RM, Swecker GS, Kullman GJ. Mortality of a cohort of U. S workers employed in the crushed stone industry, 1940-1980. Am J Ind Med. 1995;27(5):625-40.

43. Finkelstein MM. Radiographic abnormalities and the risk of lung cancer among workers exposed to silica dust in Ontario. Can Med Assoc J. 1995; 152(1):37-43.

44. Finkelstein MM, Verma DK. Mortality among Ontario members of the International Union of Bricklayers and Allied Craftworkers. Am J Ind Med. 2005;47(1):4-9.

45. Forastiere F, Lagorio S, Michelezzi P, Perucci CA, Axelson O. Mortality pattern of silicotic subjects in the Latium region. Italy Br J Ind Med. 1989:46(12):877-80.

46. Fu H, Gu X, Yu S, Wu K, Guidotti TL. Lung cancer among tin miners in Southeast China: silica exposure, silicosis, and cigarette smoking. Am J Ind Med. 1994;26(3):373-81.

47. Gallagher LG, Park RM, Checkoway H. Extended follow-up of lung cancer and non-malignant respiratory disease mortality among California diatomaceous earth workers. Occup Environ Med. 2015;72(5):360-5.

48. Giordano F, Dell'orco V, Fantini F, Grippo F, Perretta V, Testa A, et al. Mortality in a acohort of cement workers in a plant of Central Italy. Int Arch Occup Environ Health. 2012;85(4):373-9.

49. Goldsmith DF, Beaumont JJ, Morrin LA, Schenker MB. Respiratory cancer and other chronic disease mortality among silicotics in California. Am J Ind Med. 1995;28(4):459-67.

50. Grabber JM, Stayner LT, Cohen RA, Conroy LM, Attfield MD. Respiratory disease mortality among US coal miners; results after 37 years of follow-up. Occup Environ Med. 2014;71(1):30-9.

51. Graham WG, Costello J, Vacek PM. Vermont granite mortality study: an update with an emphasis on lung cancer. J Occup Environ Med. 2004;46(5):459-66
52. Guenel P, Hojberg G, Lynge E. Cancer incidence among Danish stone workers. Scand J Work Environ Health. 1989;15(4):265-70.

53. Hodgson JT, Jones RD. Mortality of a cohort of tin miners 1941-86. $\mathrm{Br} J$ Ind Med. 1990;47(10):665-76.

54. Infante-Rivard C, Armstrong B, Petitclerc M, Cloutier LG, Theriault G. Lung cancer mortality and silicosis in Quebec, 1938-1985. Lancet. 1989;2(8678-8679):1504-7

55. Kachuri L, Villeneuve PJ, Parent ME, Johnson KC, the Canadian Cancer Registries Epidemiology Group, Harris LA. Occupational exposure to crystalline silica and the risk of lung cancer in Canadian men. Int J Cancer. 2014;135:138-48.

56. Kauppinen T, Heikkila P, Partanen T, Virtanen SV, Pukkala E, Ylostalo P, et al. Mortality and cancer incidence of workers in Finnish road paving companies. Am J Ind Med. 2003;43(1):49-57.

57. Kinlen $\sqcup$, Willows AN. Decline in the lung cancer hazard: a prospective study of the mortality of iron ore miners in Cumbria. Br J Ind Med. 1988; 45(4):219-24.

58. Koh DH, Kim TW, Jang SH, Ryu HW. Cancer mortality and incidence in cement industry workers in Korea. Saf Health Work. 2011;2(3):243-9.

59. Koskela RS, Klockars M, Laurent H, Holopainen M. Silica dust exposure and lung cancer. Scand J Work Environ Health. 1994;20(6):407-16.

60. Kusiak RA, Springer J, Ritchie AC, Muller J. Carcinoma of lung in Ontario gold miners: possible aetiological factors. Br J Ind Med. 1991;48(12):808-17.

61. Lagorio S, Forastiere F, Michelozzi P, Cavariani F, Perucchi CA, Axelson O. A case-referent study on lung cancer mortality among ceramic workers. IARC Sci Publ. 1990;97:21-8.

62. Lawler AB, Mandel JS, Schuman LM, Lubin JH. A retrospective cohort mortality study of iron ore (haematite) miners in Mineesota. J Occup Med. 1985;27(7):507-17

63. Marinaccio A, Scarselli A, Gorini G, Chellini E, Mastrantonio M, Uccelli R. Retrospective mortality cohort study of Italian workers compensated for silicosis. Occup Environ Med. 2006;63(11):762-5.

64. Mehnert WH, Staneczek W, Mohner M, Konetzke G, Muller W, Ahlendorf W, et al. A mortality study of a cohort of slate quarry workers in the German Democratic Republic. IARC Sci Publ. 1990;97:55-64.

65. Meijers JM, Swaen GM, Slangen JJ. Mortality and lung cancer in ceramic workers in The Netherlands: preliminary results. Am J Ind Med. 1996;30(1): $26-30$.

66. Merlo F, Costantini M, Reggiardo G, Ceppi M, Puntoni R. Lung cancer risk among refractory brick workers exposed to crystalline silica: a retrospective cohort study. Epidemiology. 1991;2(4):299-305.

67. Merlo F, Fontana L, Reggiardo G, Ceppi M, Barisione G, Garrone E, et al. Mortality among silicotics in Genoa, Italy, from 1961 to 1987. Scand J Work Environ Health. 1995;21 Suppl 2:77-80.

68. Miller BG, MacCalman L. Cause-specific mortality in British coal workers and exposure to respirable dust and quartz. Occup Environ Med. 2010;67(4):270-6.

69. Moulin JJ, Clavel T, Roy D, Dananche B, Marquis N, Fevotte J, et al. Risk of lung cancer in workers producing stainless steel and metallic alloys. Int Arch Occup Environ Health. 2000;73(3):171-80.

70. Neuberger M, Westphal G, Bauer P. Long-term effect of occupational dust exposure. Japanese J Ind Health. 1988;30(5):362-70.

71. Ng TP, Chan SL, Lee J. Mortality of a cohort of men in a silicosis register: further evidence of an association with lung cancer. Am J Ind Med. 1990;17(2):163-71

72. Olsen GW, Andres KL, Johnson RA, Buehrer BD, Holen BM, Morey SZ, et al. Cohort mortality study of roofing granule mine and mill workers. Part II. Epidemiologic analysis, 1945-2004. J Occup Environ Hyg. 2012;9(4):257-68.

73. Partanen T, Pukkala E, Vainio H, Kurppa K, Koskinen H. Increased incidence of lung and skin cancer in Finnish silicotic patients. J Occup Med. 1994;36(6):616-22.

74. Peters S, Reid A, Fritschi L, Musk AW, de Klerk N. Cancer incidence and mortality among underground and surface goldminers in Western Australia. Br J Cancer. 2013;108(9):1879-82.

75. Pham QT, Gaertner M, Mur JM, Braun P, Gabiano M, Sadoul P. Incidence of lung cancer among iron miners. Eur J Respir Dis. 1983;64(7):534-40.

76. Preller L, Van den Bosch LM, Van den Brandt PA, Kaupinen T, Goldbohm A. Occupational exposure to silica and lung cancer risk in the Netherlands. Occup Environ Med. 2010;67(10):657-63.

77. Rafnsson V, Gunnarsdottir H. Lung cancer incidence among an Icelandic cohort exposed to diatomaceous earth and cristobalite. Scand J Work Environ Health. 1997;23(3):187-92. 
78. Reid PJ, Sluis-Cremer GK. Mortality of white South African gold miners. Occup Environ Med. 1996;53(1):11-6.

79. Rodriguez V, Tardon A, Kogevinas M, Prieto CS, Cueto A, Garcia M, et al. Lung cancer risk in iron and steel foundry workers: a nested case-contro study in Asturias. Spain Am J Ind Med. 2000;38(6):644-50.

80. Samet JM, Pathak DR, Morgan MV, Coultas DB, James DS, Hunt WC. Silicosis and lung cancer risk in underground uranium miners. Health Phys. 1994; 66(4):450-3.

81. Scarselli A, Binazzi A, Forastiere F, Cavariani F, Marinaccio A. Industry and job-specific mortality after occupational exposure to silica dust. Occup Med (Lond). 2011;61(6):422-9.

82. Schuler G, Walchi P, Ruttner JR, Delmore M, Taylor M, Schnieper R. Incidence of lung cancer and age at death in silicosis deaths of the Swiss National Accident Insurance Fund, 1960-1978. Soz Praventivmed. 1982:27(5):218-9.

83. Sherson D, Svane O, Lynge E. Cancer incidence among foundry workers in Denmark. Arch Environ Health. 1991:46(2):75-81.

84. Smailyte G, Kurtinaitis J, Andersen A. Mortality and cancer incidence among Lithuanian cement producing workers. Occup Environ Med. 2004;61(6):529-34

85. Steenland K, Brown D. Mortality study of gold miners exposed to silica and nonasbestiform amphibole minerals: an update with 14 more years of follow-up. Am J Ind Med. 1995;27(2):217-29.

86. Steenland K, Sanderson W. Lung cancer among industrial sand workers exposed to crystalline silica. Am J Epidemiol. 1982;11(2):175-80.

87. Thomas TL. Lung cancer mortality among pottery workers in the United States. IARC Sci Publ. 1990;97:75-81.

88. Tornling G, Hogstedt C, Westerholm P. Lung cancer incidence among Swedish ceramic workers with silicosis. IARC Sci Publ. 1990;97:113-9.

89. Tse LA, Yu IT, Qiu H, Au JS, Wang XR. Occupational risks and lung cancer burden for Chinese men: a population-based case-referent study. Cancer Causes Control. 2012;23(1):121-31.

90. Tse LA, Yu IT, Qiu H, Leung CC. Joint effects of smoking and silicosis on diseases to the lungs. PLoS One. 2014;9(8):e104494.

91. Tsuda T, Mino Y, Babazono A, Shigemi J, Otsu T, Yamamoto E, et al. A case-control study of lung cancer in relation to silica exposure and silicosis in a rural area in Japan. Ann Epidemiol. 2002;12:288-94.

92. Ulm K, Gerein P, Eigenthaler J, Schmidt S, Ehnes H. Silica, silicosis and lung cancer:: results from a cohort study in the stone and quarry industry. Int Arch Occup Environ Health. 2004;77(5):313-8.

93. Ulm K, Waschulzik B, Ehnes H, Guldner K, Thomasson B, Schwebig A, et al. Silica dust and lung cancer in the German stone, quarrying, and ceramics industries: results of a case-control study. Thorax. 1999;54(4):347-51.

94. Vacek PM, Verma DK, Graham WG, Callas PW, Gibbs GW. Mortality in Vermont granite workers and its association with silica exposure. Occup Environ Med. 2011;68(5):312-8.

95. Vida S, Pinto J, Parent ME, Lavoué J, Siemiatycki J. Occupational exposure to silica and lung cancer: pooled analysis of two case-control studies in Montreal Canada. Cancer Epidemiol Biomarkers Prev. 2010;19:1602-11.

96. Wang Z, Dong D, Liang X, Qu G, Wu J, Xu X. Cancer mortality among silicotics in China's metallurgical industry. Int J Epidemiol. 1996;25(5): 913-7.

97. Watkins DK, Chiazze L, Fryar CD, Fayerweather W. A case-control study of lung cancer and non-malignant respiratory disease among employees in asphalt roofing, manufacturing and asphalt production. J Occup Environ Med. 2002;44(6):551-8

98. Westburg H, Andersson L, Bryngelsson IL, Ngo Y, Ohlson CG. Cancer morbidity and quartz exposure in Swedish iron foundries. Int Arch Occup Environ Health. 2013;86(5):499-507.

99. Westerholm P, Ahlmark A, Maasing R, Segelberg I. Silicosis and risk of lung cancer or lung tuberculosis: a cohort study. Environ Res. 1986:41(1):339-50.

100. Wiebert $P$, Alderling M, Svartengren M, Gustavsson P, Plato N. Cancer, mortality and myocardial infarction in workers exposed to respirable crystalline silica dust at a Swedish porcelain factory. Occup Environ Med. 2014;71 Suppl 1:A31.

101. Xu Z, Brown LM, Pan GW, Liu TF, Gao GS, Stone BJ, et al. Cancer risks among iron and steel workers in Anshan, China, Part I: Proportional mortality ratio analysis. Am J Ind Med. 1996;30(1):1-6.

102. Yu I, Tse LA, Chi CL, Tze WW, Cheuk MT, Alan CC. A retrospective cohort study on mortality among silicotic workers in Hong Kong with emphasis on lung cancer. Chin J Occup Hyg Occup Dis. 2008;26(1):29-33.
103. Zambon P, Simonato L, Mastrangelo G, Winkelmann R, Saia B, Crepet M. Mortality of workers compensated for silicosis during the period 1959-1963 in the Veneto regionof Italy. Scand J Work Environ Health. 1987;13(2):118-23.

104. Zhang X, Wang H, Zhu X, Liu Y, Wang L, Dai Q, et al. Cohort mortality study in three ceramic factories in Jingdezhen in China. J Huazhong Univ Sci Technolog Med Sci. 2008;28(4):386-90.

105. Puntoni R, Goldsmith DF, Valerio F, Vercelli M, Bonassi S, Di Giorgio F, et al. A cohort study of workers employed in a refractory brick plant. Tumori. 1988;74(1):27-33.

106. Erren TC, Glende CB, Morfeld P, Piekarski C. Is exposure to silica associated with lung cancer in the absence of silicosis? A meta-analytical approach to an important public health question. Int Arch Occup Environ Health. 2009; 82(8):997-1004

107. Kurihara N, Wada O. Silicosis and smoking strongly increase lung cancer risk in silica-exposed workers. Ind Health. 2004:42(3):303-14.

108. Pelucchi C, Pira E, Piolatto G, Coggiola M, Carta P, La Vecchia C. Occupational silica exposure and lung cancer risk: a review of epidemiological studies 1996-2005. Ann Oncol. 2006;17(7):1039-50.

109. Steenland K, Stayner L. Silica, asbestos, man-made mineral fibers, and cancer. Cancer Causes Control. 1997;8(3):491-503.

110. Tsuda T, Babazono A, Yamamoto E, Mino Y, Matsuoka H. A meta-analysis on the relationship between pneumoconiosis and lung cancer. J Occup Health. 1997;39(4):285-94.

111. Smith AH, Lopipero PA, Barroga VR. Meta-analysis of studies of lung cancer among silicotics. Epidemiology. 1995;6:617-24.

112. Harrison J, Chen JO, Miller W. Chen W, Hnizdo E, Lu J, et al. Risk of silicosis in cohorts of Chinese tin and tungsten miners and pottery workers (II): Workplace-specific silica particle surface composition. Am J Ind Med. 2005:48(1):10-5.

113. Le Bouffant L, Daniel H, Martin JC, Bruyere S. Effect of impurities and associated minerals on quartz toxicity. Ann Occup Hyg. 1982;26(1-4):625-34

114. Cocco P, Dosemeci M, Rice C. Lung cancer among silica-exposed workers: The quest of truth between chance and necessity. Med Lav. 2007:98:3-17.

115. Sica GT. Bias in research studies. Radiology. 2006;238(3):780-9.

\section{Submit your next manuscript to BioMed Central and we will help you at every step:}

- We accept pre-submission inquiries

- Our selector tool helps you to find the most relevant journal

- We provide round the clock customer support

- Convenient online submission

- Thorough peer review

- Inclusion in PubMed and all major indexing services

- Maximum visibility for your research

Submit your manuscript at www.biomedcentral.com/submit 